\title{
Answer to: Letter to the Editor titled is telemedicine a worldwide trend?
}

\author{
Everett F. Magann · Janet Bronstein • \\ Samantha S. McKelvey $\cdot$ Paul Wendel • \\ Dora M. Smith · Curtis L. Lowery
}

Received: 3 February 2014 / Accepted: 7 February 2014 / Published online: 25 February 2014

(C) Springer-Verlag Berlin Heidelberg 2014

We would like to thank Drs. Tae-Hee Kim and Hae-Hyeog Lee for their letter about our article discussing maternal fetal medicine referrals using telemedicine in a rural state in the United States [1]. The use of telemedicine is much more widespread in the state of Arkansas as compared to the rest of the United States. Specifically in pregnancy, telemedicine is used for the management of at-risk patients with medical complications of pregnancy, the performance of targeted ultrasound examinations of the fetus and genetic consults, and fetal echocardiography.

Drs. Tae-Hee Kim and Hae-Hyeog Lee have asked several probing questions about what is needed to establish the system, what is the importance of telemedicine, how other countries might implement this type of system, reimbursement for services, and legal problems. An interconnected system that rapidly transmits data is essential to the success of telemedicine. Currently, all of the hospitals in our state are interconnected with $\mathrm{T} 1$ telecommunication lines, which are fiber optic lines capable of the transfer of large amounts of data very rapidly. There are additional costs for equipment at both the receiving and transmitting sites, but the primary cost is the initial establishment of the fiber optic system. A recent grant has allowed expansion of telemedicine services to all of the health deparments in our state. In our rural state in which 42,000 deliveries occur each year,

E. F. Magann $(\bowtie) \cdot$ S. S. McKelvey $\cdot$ P. Wendel · D. M. Smith ·

C. L. Lowery

Department of Obstetrics and Gynecology, University

of Arkansas for the Medical Sciences, 4301 W. Markham Street,

Slot \# 518, Little Rock, AR 72205, USA

e-mail: efmagann@uams.edu

J. Bronstein

Department of Healthcare Organization and Policy, University

of Alabama, Birmingham, Birmingham, AL, USA telemedicine has enabled the four maternal fetal medicine physicians at the University to be available and accessible to the rest of the health care providers in the state. Reimbursement for telemedicine services first became available in the US in 1999 [2] and by 2004, 34 out of the 50 states were receiving reimbursement for telemedicine services. Legal issues to date have not been a problem with our telemedicine service.

The challenge for the future in telemedicine is that although this technology appears promising and allows access to populations in rural areas, studies validating that telemedicine is at least equivalent to on-site (face to face) treatment are still lacking. A number of investigations are underway at our University to evaluate telemedicine vs. onsite patient care.

Conflict of interest The author reports no conflict of interest to disclose.

\section{References}

1. Magann EF, Bronstein J, McKelvey SS, Wendel P, Smith DM, Lowery CL (2012) Evolving trends in maternal fetal medicine referrals in a rural state using telemedicine. Arch Gynecol Obstet 286(6):1383-1392

2. Covered medical and other health services, Part 272.02-List of medicare telehealth services. Medicare benefit policy manual CMS internet only manual 100-02. Chap 15 